\title{
Invited Commentary on the Paper Entitled 'Methicillin-Resistant Staphylococcus aureus Infection: An Independent Risk Factor for Mortality in Patients with Poststernotomy Mediastinitis'
}

\author{
Pascal M.C.E. Dohmen \\ Department of Cardiac Surgery, Heart Center Leipzig, University of Leipzig, Leipzig, Germany; \\ Department of Cardiothoracic Surgery, University of the Free State, Bloemfontein, South Africa
}

While post-sternotomy mediastinitis (PSM) is a rare complication, it is a most serious surgical site infection (SSI) with high mortality. This devastating complication has an enormous influence on the patients' quality of life, associated with extended hospitalization, multiple additional surgeries and prolonged application of antibiotic therapy. If there is a multi-resistant microbe or multiple resistant microbes involved, the antibiotic options are limited, which further decreases the survival rate. Therefore, maximum efforts should be made to prevent SSI, including mediastinitis.

Yavuz et al. [1] investigated independent risk factors in patients suffering from PSM. The study clearly showed that improvement of infection control interventions can dramatically decrease SSI rates. Unfortunately, the preventive measures had already been published in a previous study, in which the authors explained the local institutional improvements and modifications of preventive strategies [2]. Preoperative screening and intranasal treatment of elective patients, including carriers of methicillin-sensitive Staphylococcus aureus (MRSA), were initiated to decolonize preoperative cardiac patients. Additionally, that study showed that alcohol-based solutions are mandatory for reducing SSI, including a preoperative antiseptic shower using 4\% chlorhexidine. Furthermore, vancomycin was added to the antibiotic prophylaxis in patients undergoing prosthetic valve or graft implantation. However, care should be taken when vancomycin is included for prophylaxis as the correct dose, the timing of the application ( $2 \mathrm{~h}$ before skin incision) and the duration of administration $(\sim 1 \mathrm{~h})$ are crucial to ensuring the maximum effect. Disadvantages of this regime are the development of microbial resistance, which is of great importance since the authors claim that vancomycin is still the first choice of treatment for MRSA infections.

Questionable is also the unrestricted administration of intranasal mupirocin to all patients regardless of colonization the day before surgery, as previous articles have been published concerning bacterial resistance against mupirocin.

Another critical issue discussed in the article is PSM in combination with prosthetic valve endocarditis and the underestimated number of patients. The operative mortality in these patients is extremely high; however, without surgery, a statistically significant increase in mortality was found. A similar profile is seen in patients undergoing transcatheter valve implants, who are inoperable and receive antibiotic therapy if they develop active infective endocarditis. In these patients, surgical treatment in combination with adequate antibiotic therapy increases

\begin{tabular}{ll}
\hline KARGER & $\begin{array}{l}\text { ( ) 2014 S. Karger AG, Basel } \\
1011-7571 / 14 / 0236-0524 \$ 39.50 / 0 \quad \text { Karger }\end{array}$ \\
$\begin{array}{l}\text { E-Mail karger@karger.com } \\
\text { www.karger.com/mpp }\end{array}$ & $\begin{array}{l}\text { Thisis an Open Access article licensed under the terms of the } \\
\text { Creative Commons Attribution-NonCommercial 3.0 Un- } \\
\text { ported license (CC BY-NC) (www.karger.com/OA-license), } \\
\text { applicable to the online version of the article only. Distribu- } \\
\text { tion permitted for non-commercial purposes only. }\end{array}$
\end{tabular}

Pascal M.C.E. Dohmen, MD, PhD

Charité Hospital, Medical University Berlin

Department of Cardiovascular Surgery, Chariteplatz 1

DE-10117 Berlin (Germany)

E-Mail pascal.dohmen@yahoo.de 
survival and therefore this should also be considered as a potential option for patients suffering from PSM with active infective endocarditis. The authors also suggested that active infective prosthetic valve endocarditis could be underestimated and that therefore in patients suffering from PSM echocardiographic examination should be performed to evaluate the implanted prosthetic valve, and if there is clear evidence of endocarditis (assessed via the modified Duke criteria) one should also consider surgery to treat the prosthetic valve. Even if the mortality is very high, the only adequate antibiotic therapy seems insufficient, as survival data showed. This study also supports the finding that delayed appropriate antibiotic therapy will result in a statistically significant increase in mortality [1].

Nevertheless, the authors should be congratulated for their effort in implementing improvement of infection control interventions at their institution. MRSA mediastinitis was eradicated from their daily practice and the PSM mortality was halved.
References
Şimşek Yavuz S, Şensoy A, Çeken S, Deniz D, Yekeler I: Methicillin-resistant Staphylococcus aureus infection: an independent risk factor for mortality in patients with poststernotomy mediastinitis. Med Princ Pract DOI: $10.1159 / 000365055$
2 Yavuz SS, Tarcin O, Ada S, et al: Incidence, aetiology, and control of sternal surgical site infections. J Hosp Infect 2013;85:206-212. 